\title{
EDITORIAL
}

\section{The African-American neonate at risk for extreme hyperbilirubinemia: a better management strategy is needed}

\author{
Journal of Perinatology (2017) 37, 321-322; doi:10.1038/jp.2017.1
}

In 2010, Watchko ${ }^{1}$ summarized the clinical concerns of managing jaundiced African-American neonates. Though acknowledging the data $^{1-4}$ identifying Black/African-American infants (defined based on maternal race) as having a lower risk for significant hyperbilirubinemia, he argued that glucose-6-phosphate dehydrogenase (G6PD) deficiency, coupled with polymorphisms in genes involved in bilirubin metabolism and other factors (ABO isoimmunization, late preterm gestation and limited clinical visualization), may predispose these newborns to developing pathologic bilirubin levels. Additional studies in the United States ${ }^{5}$ and in Europe ${ }^{6}$ have verified elevated risks of extreme hyperbilirubinemia and bilirubin encephalopathy, respectively, in newborns of African descent.

In their article in this issue of the Journal, Schutzman et al. ${ }^{7}$ highlight the difficulties of genetic screening for hyperbilirubinemia in a prospective study of healthy African-American newborns. Multiple variants in the UGT1A1 and SLCO1B1 genes (which result in decreased bilirubin metabolism) were identified in their cohort; however, these variants did not correlate with the degree of hyperbilirubinemia in their patients. Furthermore, the authors acknowledge that their findings fail to provide resolution to a persistent problem faced by clinicians: identifying and caring for a small yet important fraction of African-American newborns who will have severely elevated bilirubin levels, putting them at an increased risk of developing short-term and long-term neurodevelopmental sequelae. Given that hyperbilirubinemia is a multigenetic process ${ }^{8,9}$ that remains incompletely understood, clinicians and scientists must address several gaps in our knowledge and management of hyperbilirubinemia in this unique population.

First, consideration should be given to identification of an infant's race and/or ethnicity based on more than the mother's self-report, as has been previously discussed regarding hyperbilirubinemia. ${ }^{10}$ In the United States currently, many parents and newborns are born of multiracial or multiethnic unions or relationships, rendering the singular classifications of 'Black/ African-American' or 'White/Caucasian' imperfect and somewhat obsolete. Additionally, a mother who self-identifies by one race may fail to acknowledge other key components of her ancestry, hindering full comprehension of her genetic composition. As previously noted, ${ }^{10,11}$ identification of children at risk for hyperbilirubinemia can be underestimated by incomplete or inaccurate documentation of a patient's background. Robust recording of ethnicity and race in medical records and health department documents using $\mathrm{NIH}$ categories and definitions (instead of traditional categorizations) and allowing for multiple designations (instead of a single check box) likely will identify more babies with African or African-American heritage, aiding in better understanding the heritable patterns of the disease.

Second, the genetics of severe hyperbilirubinemia in AfricanAmerican neonates must be elucidated fully. Paramount to this task is the introduction of rapid, mandatory neonatal screening for G6PD deficiency across the United States. The absence of significant hyperbilirubinemia in the cohort of infants in this study $^{7}$ (all but eight of which were G6PD sufficient) and the association of G6PD deficiency and other polymorphisms in bilirubin metabolism genes with significant or severe jaundice in African-American babies ${ }^{1,8,12}$ suggest an important role for early identification of this condition in this population of newborns. G6PD deficiency occurs in roughly $12 \%$ of African-American males and $4 \%$ of African-American females (based on a study of US military personnel ${ }^{13}$ ), within or well above the $3-5 \%$ male frequency threshold for screening recommended by the World Health Organization over 25 years ago. ${ }^{14}$ However, at present, only Pennsylvania (the state in which the current report was based) and the District of Columbia require routine newborn G6PD screening. While a prior article in this Journal ${ }^{11}$ highlighted the operational challenges of newborn testing for G6PD in the United States, a more recent article (again, in this Journal ${ }^{15}$ ) noted that a combination of routine screening and parental education may be the only way to reduce kernicterus associated with G6PD deficiency. Point-of-care G6PD assays ${ }^{16-17}$ have shown promise in small studies and may soon be ready for use on a larger scale in nurseries and mother-baby units. More comprehensive testing for G6PD and other genes involved in bilirubin metabolism may allow for discovery of ancestry-informative markers linked to extreme hyperbilirubinemia.

Finally, hospitals and health-care systems must establish networks to monitor these at-risk newborns closely to prevent unchecked hyperbilirubinemia and resultant bilirubin encephalopathy. Care models in $\left.\right|_{\text {srael }}{ }^{18}$ and Brazil ${ }^{19}$ utilizing stringent discharge criteria, parental education, dedicated hospital resources for outpatient bilirubin monitoring and community/ cultural based interventions have demonstrated decreases in extreme neonatal hyperbilirubinemia in these populations. At present, however, no routine outpatient/community systems exist for such monitoring in the United States, especially in the inner cities. In Baltimore City, for example, many African-American families use federally qualified health centers designed to serve the health-care needs of the underinsured and underserved. However, many of these centers offer reduced hours of service, with no or limited weekend availability. In this scenario, a neonate at risk for severe hyperbilirubinemia followed at one of these clinics might be sent to an emergency department for follow-up, possibly representing improper utilization of resources. As we better understand the inherited factors placing some AfricanAmerican neonates at risk for potential pathologic jaundice, we must ensure simultaneously that appropriate resources exist for continued care of these babies in the early neonatal period.

The AAP Clinical Practice Guidelines for management of neonatal hyperbilirubinemia ${ }^{20}$ and its 2009 update $^{21}$ remain mainstays for practitioners, particularly with the clear guidance in the latter document regarding pre-hospital bilirubin measurement and risk assessment. In most cases, African-American infants managed using these guidelines will require only routine newborn care and follow-up. However, the work of Schutzman et al. ${ }^{7}$ gives us pause to consider steps we can take as practitioners and researchers to find the outliers and minimize the risk of severe hyperbilirubinemia in African-American newborns.

\section{CONFLICT OF INTEREST}

The author declares no conflict of interest. 
WC Golden Division of Neonatology, The Johns Hopkins University School of Medicine, Baltimore, MD, USA E-mail: cgolden@jhmi.edu

\section{REFERENCES}

1 Watchko JF. Hyperbilirubinemia in African American neonates: clinical issues and current challenges. Semin Fetal Neonatal Med 2010; 15(3): 176-182.

2 Hardy JB, Drage JS, Jackson EC. The First Year of Life. The Collaborative Perinatal Project of the National Institute of Neurological and Communicative Disorders and Stroke. Johns Hopkins University Press, Baltimore, MD, USA, 1979.

3 Chou SC, Palmer RH, Ezhuthachan S, Newman C, Pradell-Boyd B, Maisels MJ et al. Management of hyperbilirubinemia in newborns: measuring performance by using a benchmarking model. Pediatrics 2003; $112(6$ pt 1): 1264-1273.

4 Newman TB, Easterling MJ, Goldman ES, Stevenson DK. Laboratory evaluation of jaundice in newborns. Frequency, cost, and yield. Am J Dis Child 1990; 144(3): 364-368.

5 Wickremasinghe AC, Kuzniewicz MW, Newman TB. Black race is not protective against hazardous bilirubin levels. J Pediatr 2013; 162(5): 1068-1089.

6 Manning D, Todd P, Maxwell M, Jane Platt M. Prospective surveillance study of severe hyperbilirubinaemia in the newborn in the UK and Ireland. Arch Dis Child Fetal Neonatal Ed 2007; 92(5): F342-F346.

7 Schutzman DL, Baudhuin LM, Ajayi S, Wong RJ. Effect of genetic variants of bilirubin metabolism on the degree of hyperbilirubinemia in African American newborns. J Perinatol 2017. (e-pub ahead of print 15 December 2016; jp.2016.232)

8 Watchko JF, Lin Z, Clark RH, Kelleher AS, Walker MW, Spitzer AR for the Pediatrix Hyperbilirubinemia Study Group. Complex multifactorial nature of significant hyperbilirubinemia in neonates. Pediatrics 2009; 124 (5):e868-e877.

9 Watchko JF, Lin Z, Clark RH, Kelleher AS, Walker MW, Spitzer AR for the Pediatrix Hyperbilirubinemia Study Group. Exploring the genetic architecture of neonatal hyperbilirubinemia. Semin Fetal Neonatal Med 2010; 15(3): 169-175.

10 Beal AC, Chou SC, Palmer RH, Testa MA, Newman C, Ezhuthachan S. The changing face of race: risk factors for neonatal hyperbilirubinemia. Pediatrics 2006; 117(5): 1618-1625.
11 Watchko JF, Kaplan M, Stark AR, Stevenson DK, Bhutani VK. Should we screen for glucose-6-phosphate dehydrogenase deficiency in the United States? J Perinatol 2013; 33(7): 499-504.

12 Herschel M, Ryan M, Gelbart T, Kaplan M. Hemolysis and hyperbilirubinemia in an African American neonate heterozygous for glucose-6-phosphate dehydrogenase deficiency. J Perinatol 2002; 22(7): 577-579.

13 Chinevere TD, Murray CK, Grant E Jr, Johnson GA, Duelm F, Hospenthal DR. Prevalence of glucose-6-phosphate dehydrogenase deficiency in U.S. Army personnel. Mil Med 2006; 171(9): 905-907.

14 WHO Working Group. Glucose-6-phosphate dehydrogenase deficiency. Bull World Health Organ 1989; 67(6): 601-611.

15 Kaplan M, Hammerman C, Bhutani VK. Parental education and the WHO neonatal G-6-PD screening program: a quarter century later. J Perinatol 2015; 35(10): 779-784.

16 Nock ML, Johnson EM, Krugman RR, Di Fiore JM, Fitzgerald S, Sandhaus LM et al. Implementation and analysis of a pilot in-hospital newborn screening program for glucose-6-phosphate dehydrogenase deficiency in the United States. J Perinatol 2011; 31(2): 112-117.

17 Bhutani VK, Kaplan M, Glader B, Cotten M, Kleinert J, Pamula V. Point-of-care quantitative measure of glucose-6-phosphate dehydrogenase enzyme deficiency. Pediatrics 2015; 136(5): e1268-e1275.

18 Kaplan M, Bromiker R, Schimmel MS, Algur N, Hammerman C. Evaluation of discharge management in the prediction of hyperbilirubinemia: the Jerusalem experience. J Pediatr 2007; 150 (4):412-417.

19 Punaro E, Mezzacappa MA, Facchini FP. Systematic follow-up of hyperbilirubinemia in neonates with a gestational age of 35 to 37 weeks. J Pediatr (Rio J) 2011; 87(4): 301-306.

20 American Academy of Pediatrics Subcommittee on Hyperbilirubinemia. Management of hyperbilirubinemia in the newborn infant 35 or more weeks of gestation. Pediatrics 2004; 114(1): 297-316.

21 Maisels MJ, Bhutani VK, Bogen D, Newman TB, Stark AR, Watchko JF. Hyperbilirubinemia the newborn infant $\geq 35$ weeks' gestation: an update with clarifications. Pediatrics 2009; 124 (4):1193-1198. 